\title{
Noise-Induced Stress Assessment by Salivary Cortisol Measurement
}

\author{
Behzad Fouladi Dehaghi ${ }^{1,}$; Parvin Nassiri ${ }^{2}$; Mohammad Reza Monazam $^{2}$; Leila Ebrahimi \\ Ghavam Abadi ${ }^{3}$; Saeed Farahani ${ }^{4}$; Gholamreza Hassanzadeh ${ }^{5}$; Mostafa Hoseini ${ }^{6}$; Motrza \\ Hesampor $^{1}$ \\ ${ }^{1}$ Department of Occupational Health, School of Public health, Ahvaz Jundishapur University of Medical Sciences, Ahvaz, IR Iran \\ ${ }_{2}^{2}$ Department of Occupational Health, School of Public health, Tehran University of Medical Sciences, Tehran, IR Iran \\ ${ }^{3}$ Department of Environmental Management, Islamic Azad University, Science and Research Branch, Ahvaz, IR Iran \\ ${ }_{4}^{4}$ Department of Audiology, School of Rehabilitation, Tehran University of Medical Sciences, Tehran, IR Iran \\ 5 Department of Audiology, School of Rehabilitation, Tehran University of Medical Sciences, Tehran, I \\ ${ }^{6}$ Department of Anatomy, School of Medicine, Tehran University of Medical Sciences, Tehran, IR Iran \\ ${ }^{*}$ Corresponding author: Behzad Fouladi Dehaghi, Department of Occupational Health, School of Public health, Ahvaz Jundishapur University of Medical Sciences, Ahvaz, IR Iran. Tel: \\ +98-6113738282, Fax: +98-6113367543, E-mail: fouladi-b@ajums.ac.ir
}

Received: February 22, 2014; Revised: March 17, 2014; Accepted: April 19, 2014

\begin{abstract}
Background: Noise exposure is known as a risk factor for hearing loss and one of its effects is noise-induced stress. Cortisol as a stress hormone is used in noise-induced stress assessments.

Objectives: The aim of this study was to measure and compare saliva cortisol concentrations in the morning and evening in normal work day and rest day in both case and control groups and to assess the association between industrial noise exposure and salivary cortisol concentrations in the two groups.

Patients and Methods: This study included 200 male participants (100 industrial workers and 100 office employees). Morning and evening saliva samples were collected at $7 \mathrm{AM}$ and $4 \mathrm{PM}$ respectively. Noise exposure levels were assessed by sound level meter and noise dosimeter. All measurements were performed in two days; rest day and then in working day. Descriptive statistics, paired and independent sample t-test and regression analysis were used with $\alpha=0.05$.

Results: There was no significant difference between morning salivary cortisol concentrations in the two groups on the rest and work days. A significant higher level was observed comparing evening cortisol concentrations in work day with rest day in worker group, but this was not observed in the control group. The evening cortisol in the working day in worker group was significantly higher than control group.

Conclusions: Our study revealed that industrial noise exposure with levels higher than $80 \mathrm{dBA}$ has a significant effect on salivary cortisol elevation.
\end{abstract}

Keywords:Hearing Loss; Noise-Induced; Noise

\section{Background}

Noise exposure is known as the main risk factor of noise induced hearing loss in industrial workers. Noise effects are very variable on human, and it can result in psychological distress and physiological reactions (1-3). Exposure to noise is not specific to working in industries and can be present in many rest-related activities and ambient conditions such as transportation (4). Many studies have shown that noise exposure has different effects rather than auditory ones. These extraauditory effects of noise can be observed on performance efficiency of intellectual, attention and memory tasks (2), which all are contributed to main causes of stress while working in a noise-polluted environment (3). Noise-induced stress has been under investigation in some working environments $(5,6)$. Activation of the hypothalamic-pituitary-adrenal axis (HPA) and subsequent secretion of cortisol are considered as major components of the physiological stress response in humans (7). In some of the studies, saliva and/or serum cortisol were assessed as a stress hormone, which its salivary secretion in normal individuals can be monitored easily as a noninvasive method compared to other forms $(5,8)$. Moreover, salivary cortisol level is a valid indicator of the plasma free cortisol concentration (9-13). Cortisol is the major glucocorticoid produced in the adrenal cortex (14). Cortisol production has a circadian rhythm, with levels peaking in the early morning and dropping to the lowest values at night (15-18). Levels rise independently of circadian rhythm in response to stress (19). In the recent years, salivary cortisol has become a popular measure of HPA activity in stress research for several reasons. First, plasma unbound (and physiological active) cortisol and salivary cortisol are highly correlated. Second, unlike urinary cortisol excretion, the time lag between changes in plasma cortisol and salivary cortisol is very short ( 1 to 2 minutes). Third, saliva flow rate has no impact on salivary cortisol levels. Finally, saliva

Copyright (c) 2014, Ahvaz Jundishapur University of Medical Sciences; Published by Kowsar. This is an open-access article distributed under the terms of the Creative Commons Attribution-NonCommercial 4.0 International License which permits copy and redistribute the material just in noncommercial usages, provided the original work is properly cited. 
samples can be easily obtained noninvasively, whereas plasma cortisol findings may be biased by venesection stress $(20,21)$.

\section{Objectives}

As a result, high levels of industrial noise, known as a main stressor, can be accessed via monitoring salivary cortisol in exposed individuals (22). Therefore, the present study was designed to; 1 ) measure and compare saliva cortisol concentrations in the morning and evening in normal work day and rest day in the two groups, and 2) assess the association between industrial noise exposure and salivary cortisol concentrations in the two groups workers.

\section{Patients and Methods}

This study included 200 male participants (100 industrial workers and 100 office employees). All volunteer participants received the information regarding the aim and scope of the study. Self-reporting general health status questionnaire was completed by the participants (3). The noise pattern in the factory was continuous noise. Morning and evening saliva samples were collected at 7:00 AM and 4:00 PM respectively and were refrigerated to be carried to the laboratory for further analysis. The sampling procedure consisted of a before-after design, so that the first round of saliva samples was collected in the two groups at rest day. The instructions to perform noise measurement and saliva sampling procedure were completely provided to the two groups. Besides, they were trained regarding recording awaking time in the morning, sampling timing, its preservation and time recording guideline. The participants received two test tubes, practical instructions and the noise dosimeter device. The participants were instructed to collect the first saliva sample at 7:00 AM and the second one at 4:00 PM. Furthermore, they were instructed to turn the noise dosimeter on shortly after awaking in the morning and turn it off at 4:00 in the evening after collection of saliva sample. All participants woke up at 6:00 to 6:15 AM in the rest and working days according to their daily routines. The second round of noise measurement and saliva sampling was performed during a normal working day, while they were all performing their usual tasks and instructed not to use ear protection devices. Saliva sampling was performed again at 7:00 am and 4:00 pm and noise exposure levels were monitored and recorded accordingly. Saliva samples were collected at 7:00 AM and 4:00 PM, with a $5 \mathrm{~mL}$ volume in clean vials. Tooth brushing, food and drink intake should be avoided 30 minutes before sampling. Demeditec Elisa kit (the mechanism is radioimmunoassay) was used for the quantitative measurement of free cortisol in saliva (Demeditec Diagnostics, Germany). The intra- and inter-assay variability rates were less than $7.1 \%$ and $6.9 \%$, respectively. A sound level meter (type 2236, Brüel \& Kjær, UK) was used to deter- mine ambient noise levels in the workplace and at the 80 locations where the participants worked. Only steadystate noise levels were recorded and work stations with peak sounds were eliminated from the study. Noise levels ranged from 80 to $88 \mathrm{dBA}$. To assess personal noise exposure of each participant, noise dosimeter (Cel-272, UK) was used. Leq as the equivalent steady sound level of a noise energy-averaged over time was calculated using the below formula (23):

$$
\text { Leq }=10 \log 10((\text { Dose } / 100)(8 / T))+85 \mathrm{dBA}
$$

Where dose $=$ a noise exposure dose, in percentage acquired in T hours, Leq = A-weighted, sound level linearly energy averaged over T hours, $\mathrm{T}=$ the sampling time, in hours, of the measurement. Examining the data of salivary cortisol showed positively skewed distributions, so logarithmic transformations were performed for all data for further statistical analyses under normal data assumptions. To investigate the difference between morning and evening cortisol concentrations, morning cortisol concentrations minus evening concentrations were calculated. Means and confidence intervals were used to present the data; all confidence intervals and $P$ values were two sided. The level of statistical significance was considered 0.05. Paired sample t-test and independent sample t-test were used in the analysis. General linear models were used in the multivariate analysis. Furthermore, linear regression models were used to investigate associations between noise exposure and evening saliva cortisol concentrations. Results were expressed mainly as regression coefficients and 95\% Confidence Interval (CI). The data analyses were performed using SPSS 19 for Windows (IBM, USA).

\section{Results}

Mean age and mean work experience in industrial workers and office employees were $39.8 \pm 6.4$ years, 17.1 \pm 6.6 years and $38.5 \pm$ 5.1years, $15.3 \pm 6.4$ years, respectively. Figure 1 to 4 show frequency distributions and Log transformed frequency distributions of morning and evening saliva cortisol levels in rest and work days in the two groups, respectively. For all the 200 participants on the rest day, morning salivary cortisol was significantly higher than evening cortisol $(\mathrm{P}<0.05)$. According to Table 1, no significant difference was obtained for morning cortisol levels between rest day and working day in the two groups $(\mathrm{P}=0.117, \mathrm{P}=0.12)$. In the workers group, evening cortisol concentrations showed a strong significant difference (higher level) between rest day and working day measurements $(\mathrm{P}<0.001)$, but in the control group, such difference was not observed. Besides, the difference between morning and evening cortisol concentrations at rest day samples was significantly higher than that of working day (just observed in workers group) ( $\mathrm{P}<$ 0.001). Table 2 shows that there were no significant difference in comparing saliva cortisol concentrations in morning and evening samples of the two groups. Again such result was seen for work day morning samples, but 
not for evening samples of work day. Evening saliva cortisol concentrations of work day of the workers group was significantly higher than that of control group $(\mathrm{P}<$ 0.001 ). Table 3 shows linear regression coefficients and 95\% CIs for cortisol levels in saliva from evening samples based on noise levels (Leq, 8h). As the table, shows, there was no association between noise level lower than 75 $\mathrm{dBA}$ in rest day of both groups and evening saliva cortisol concentrations. However, there was a strong significant association between noise exposure levels higher than $80 \mathrm{dBA}$ and evening salivary cortisol concentration assessed in the working day.
$1 \mathrm{~A}$

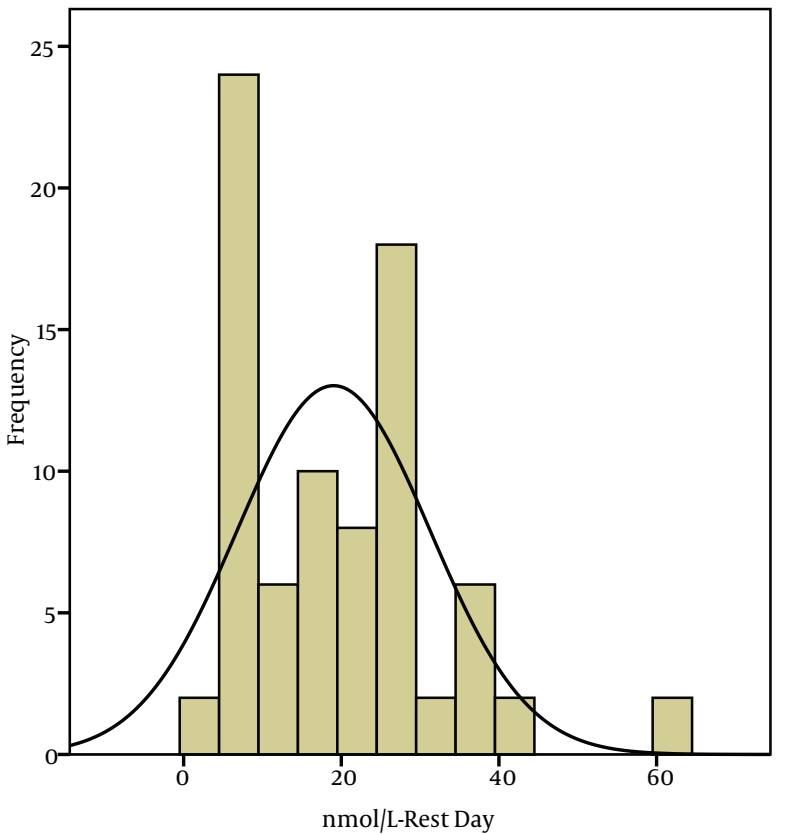

$1 \mathrm{C}$

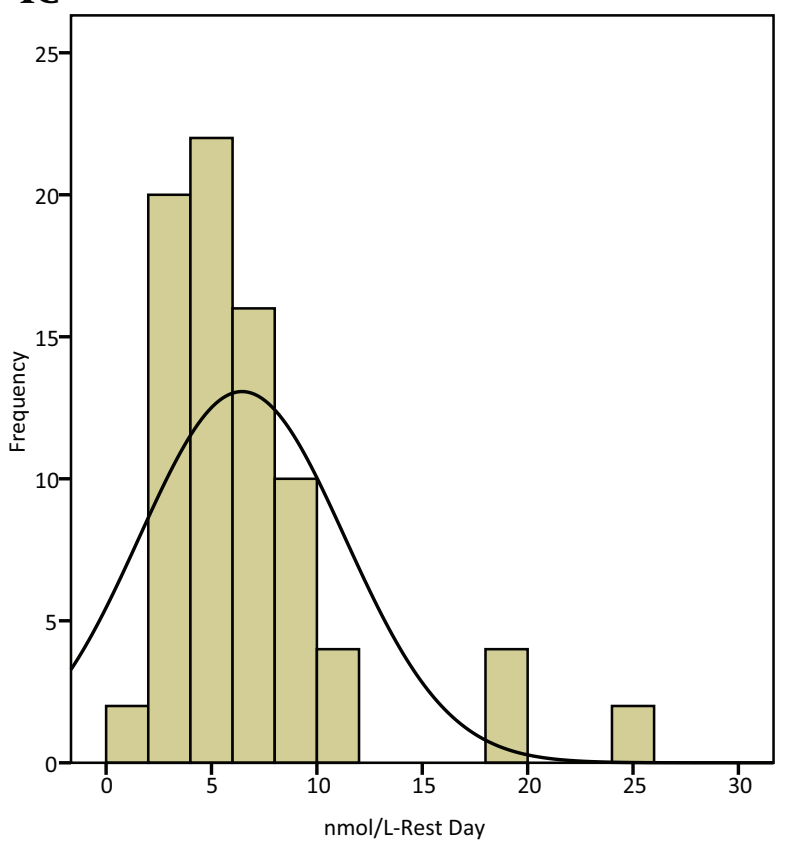

$1 \mathbf{B}$

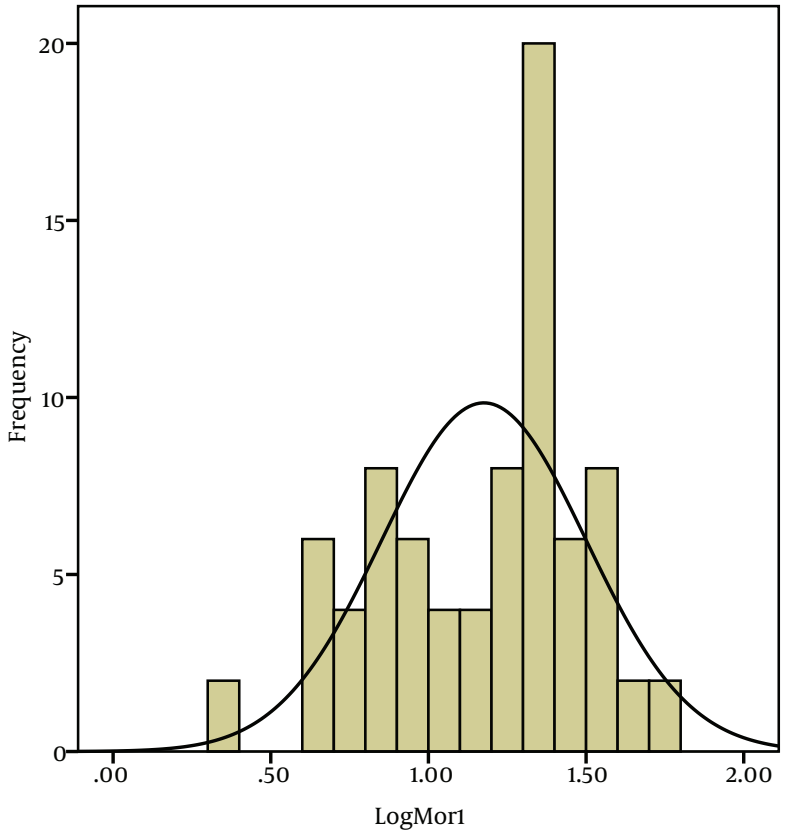

$1 D$

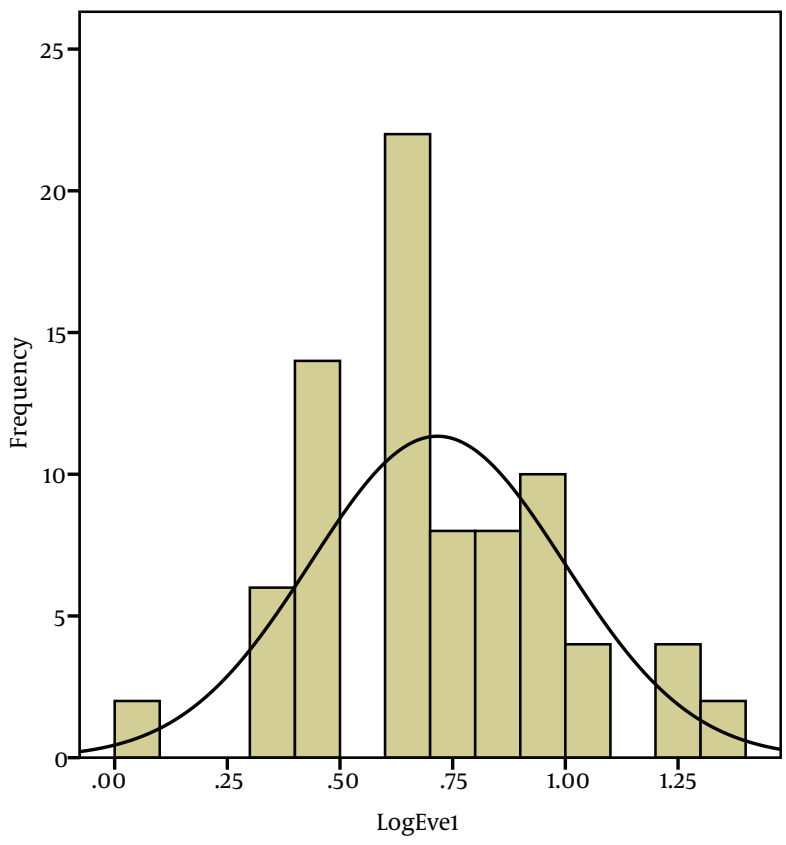

Figure 1. In Workers Group (A) Untransformed Frequency Distribution of morning Saliva Cortisol Levels in Rest Day; (B) Log Transformed Frequency Distribution of Morning Saliva Cortisol Levels in Rest Day; (C)Untransformed Frequency Distribution of Evening Saliva Cortisol Levels in Rest Day; (D) Log Transformed Frequency Distribution of Evening Saliva Cortisol Levels in Rest Day. 

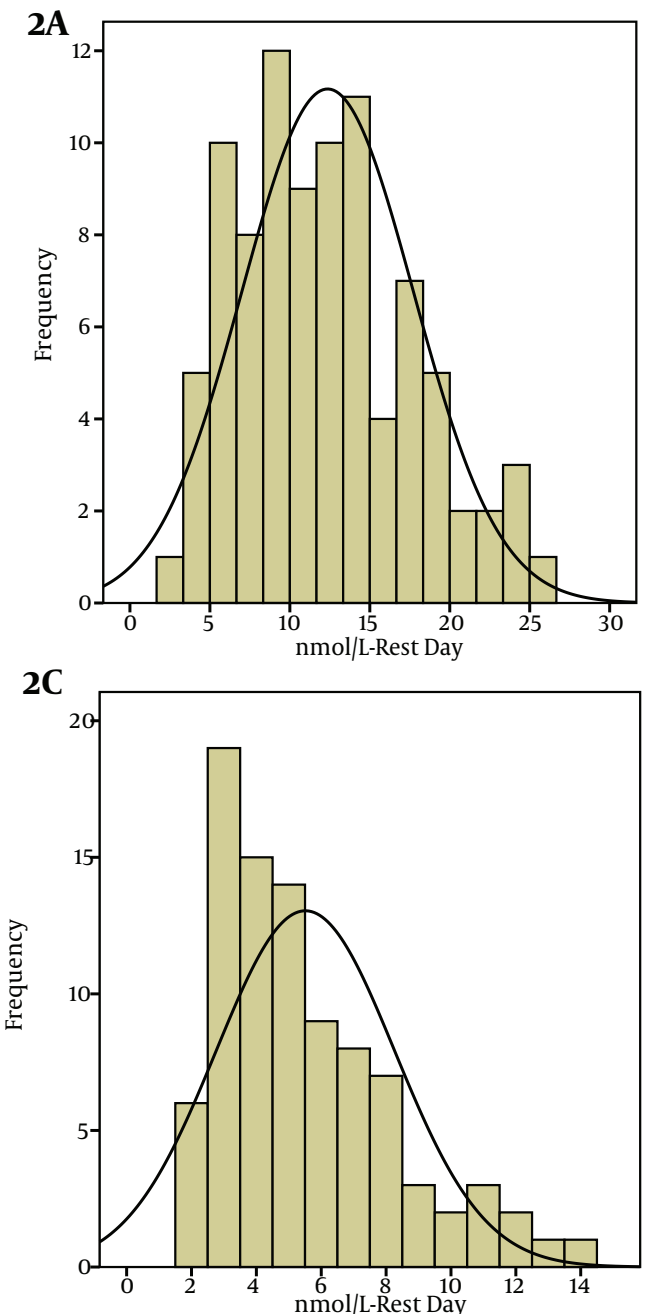
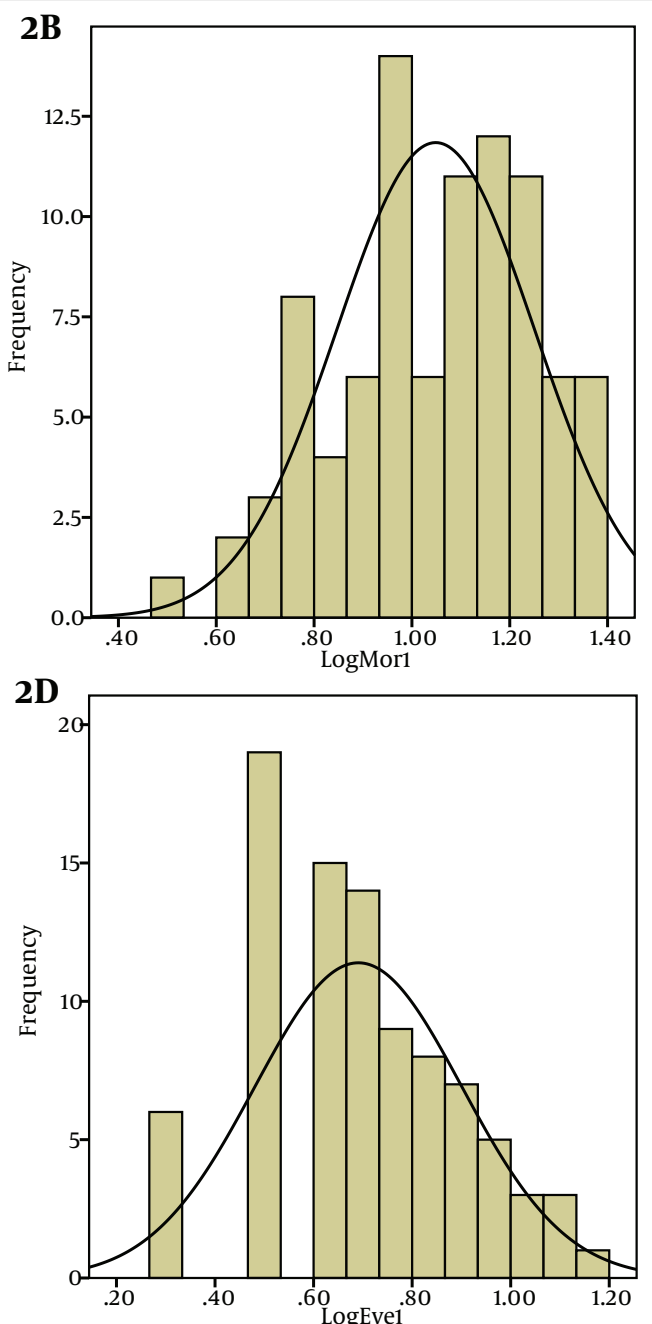

Figure 2. In Control Group (A) Untransformed Frequency Distribution of Morning Saliva Cortisol Levels in Rest Day. (B) Log Transformed Frequency Distribution of Morning Saliva Cortisol Levels in Rest Day. (C) Untransformed Frequency Distribution of Evening Saliva Cortisol Levels in Rest Day. (D) Log Transformed Frequency Distribution of Evening Saliva Cortisol Levels in Rest Day.
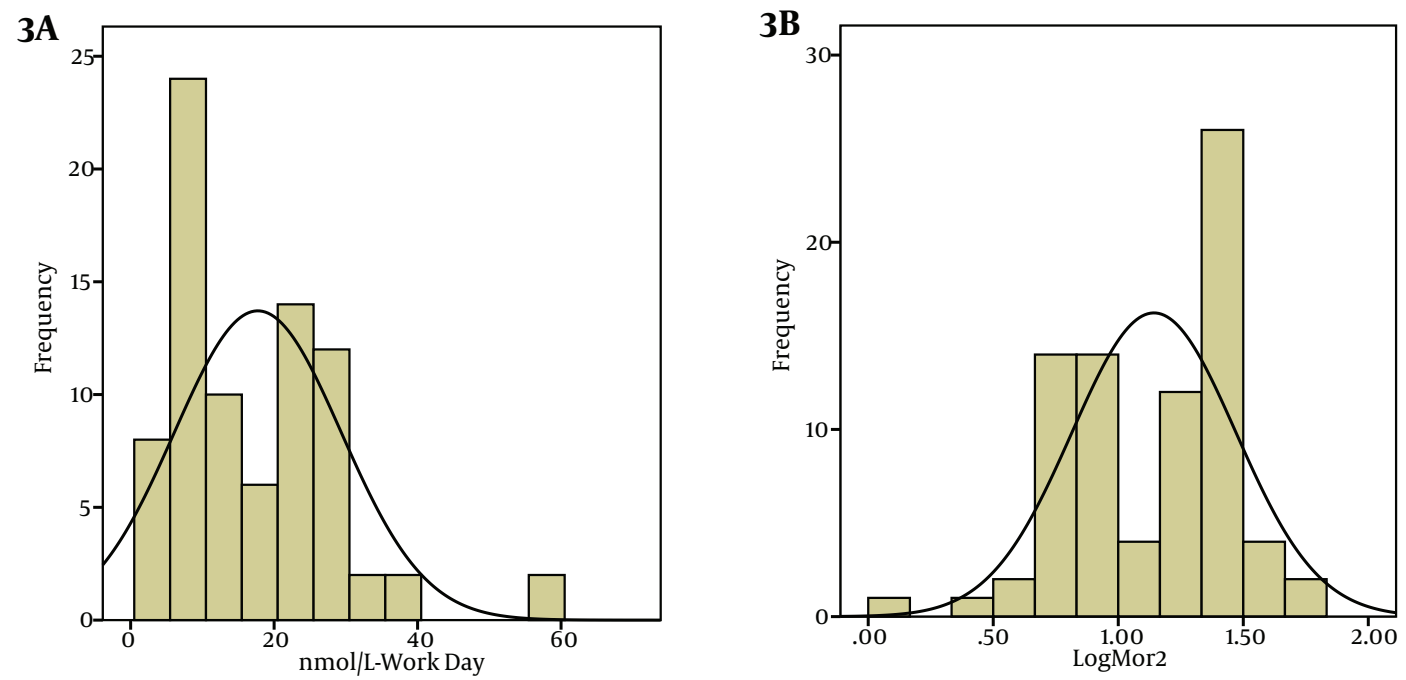

Figure 3. In workers Group (A) Untransformed Frequency Distribution of Morning Saliva Cortisol Levels in Working Day. (B) Log Transformed Frequency Distribution of Morning Saliva Cortisol Levels in Working Day. (C) Untransformed Frequency Distribution of Evening Saliva Cortisol Levels in Working Day. (D) Log Transformed Frequency Distribution of Evening Saliva Cortisol Levels in Working Day. 

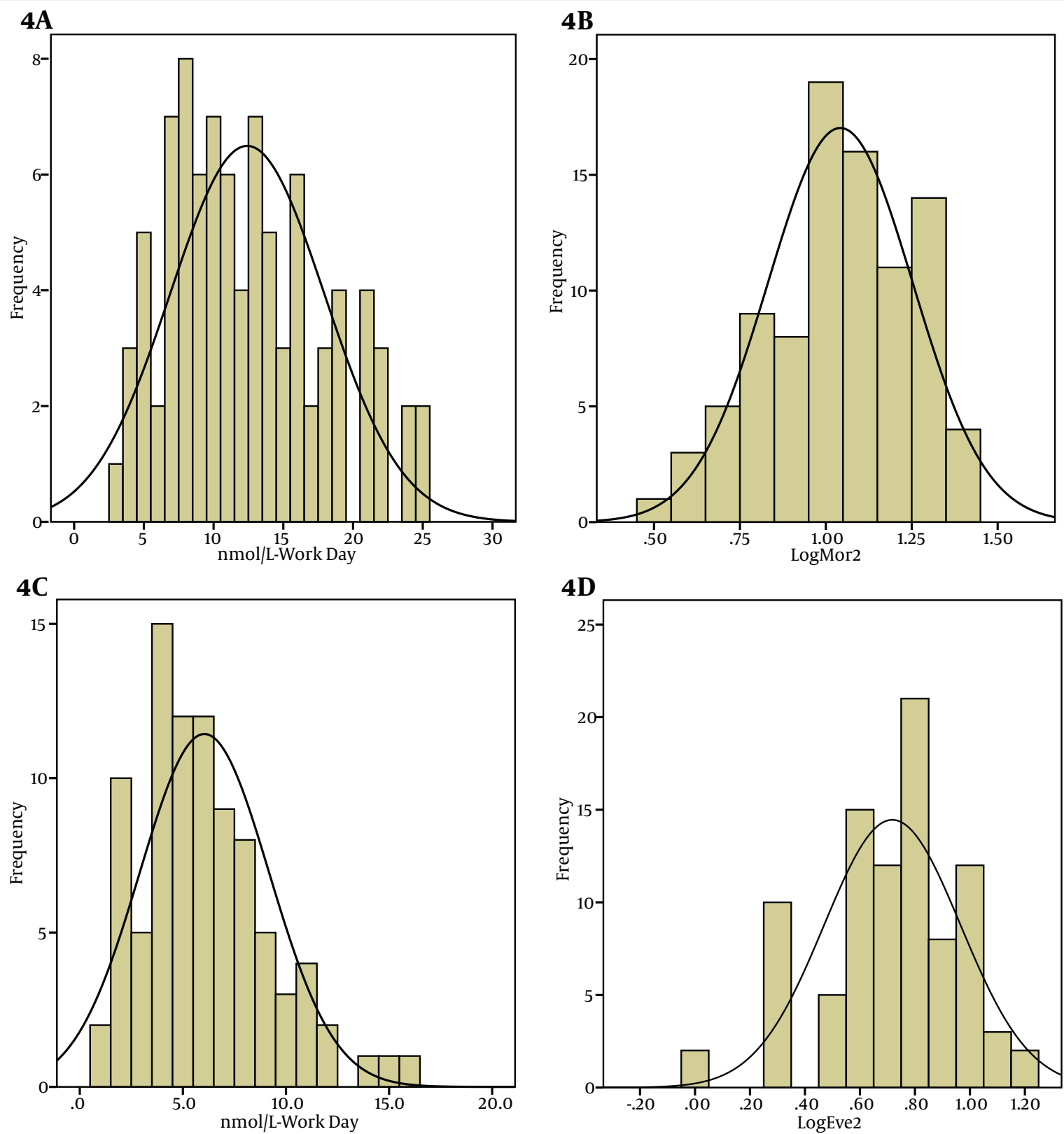

Figure 4. In Control Group (A) Untransformed Frequency Distribution of Morning Saliva Cortisol Levels in Working Day. (B) Log Transformed Frequency Distribution of Morning Saliva Cortisol Levels in Working Day. (C) Untransformed Frequency Distribution of Evening Saliva Cortisol Levels in Working Day. (D) Log Transformed Frequency Distribution of Evening Saliva Cortisol Levels in Working Day.

Table 1. Comparison of Salivary Cortisol Concentrations in Morning and Evening Samples of Rest Day and Working Day of Study Population (Case and Control) ${ }^{\mathrm{a}}$

\begin{tabular}{|c|c|c|c|c|c|c|c|c|c|c|}
\hline & \multicolumn{5}{|c|}{ Case Group } & \multicolumn{5}{|c|}{ Control Group } \\
\hline & \multicolumn{2}{|c|}{ Rest day } & \multicolumn{2}{|c|}{ Work day } & \multirow[t]{2}{*}{ PValue $^{\mathrm{b}}$} & \multicolumn{2}{|c|}{ Rest day } & \multicolumn{2}{|c|}{ Workday } & \multirow[t]{2}{*}{ PValue $^{\mathrm{b}}$} \\
\hline & GM & 95\% CI & GM & 95\% CI & & GM & 95\% CI & GM & 95\% CI & \\
\hline Morning cortisol concentration & 15.0 & $12.0-19.0$ & 14.0 & $11.25-17.6$ & 0.117 & 12.3 & $11.2-13.5$ & 12.4 & $11.2-13.7$ & 0.12 \\
\hline Evening cortisol concentration & 5.2 & $4.2-6.3$ & 8.0 & $6.5-10.2$ & 0.001 & 5.5 & $4.9-6.1$ & 6 & 5.4-6.7 & 0.1 \\
\hline Morning and evening difference ${ }^{c}$ & 9.8 & $7.0-12.0$ & 6 & $4.0-7.0$ & 0.001 & 6.8 & $6.1-7.6$ & 6.4 & $6.1-7.6$ & 0.14 \\
\hline
\end{tabular}

\footnotetext{
${ }^{\mathrm{a}}$ Abbreviations: CI, confidence interval; GM, Geometric Mean.

${ }_{\mathrm{b}} \mathrm{P}$ value was calculated using paired sample t-test.

${ }^{\mathrm{c}}$ The morning and evening difference was calculated by morning minus evening cortisol concentration $(\mathrm{nmol} / \mathrm{L})$.
} 
Fouladi Dehaghi B et al.

Table 2. Comparison of Salivary Cortisol Concentrations Between Rest Day and Working Day of Case and Control Groups

\begin{tabular}{|c|c|c|c|c|c|c|c|c|c|c|}
\hline & \multicolumn{5}{|c|}{ Rest Day } & \multicolumn{5}{|c|}{ Work Day } \\
\hline & \multicolumn{2}{|c|}{ Worker } & \multicolumn{2}{|c|}{ Control } & \multirow[t]{2}{*}{ PValue $^{\mathrm{a}}$} & \multicolumn{2}{|c|}{ Worker } & \multicolumn{2}{|c|}{ Control } & \multirow[t]{2}{*}{ PValue $^{a}$} \\
\hline & GM & 95\% CI & GM & 95\% CI & & GM & $\mathbf{9 5} \% \mathrm{CI}$ & GM & 95\% CI & \\
\hline $\begin{array}{l}\text { Morning cortisol } \\
\text { concentration }\end{array}$ & 15.0 & $12.0-19.0$ & 12.3 & $11.2-13.5$ & 0.1 & 14.0 & $11.25-17.6$ & 12.4 & $11.2-13.7$ & 0.22 \\
\hline $\begin{array}{l}\text { Evening cortisol } \\
\text { concentration }\end{array}$ & 5.2 & $4.2-6.3$ & 5.5 & $4.9-6.1$ & 0.34 & 8.0 & $6.5-10.2$ & 6 & $5.4-6.7$ & 0.05 \\
\hline $\begin{array}{l}\text { Morning and evening } \\
\text { difference }\end{array}$ & 9.8 & $7.0-12.0$ & 6.8 & $6.1-7.6$ & 0.18 & 6 & $4.0-7.0$ & 6.4 & $6.1-7.6$ & 0.4 \\
\hline
\end{tabular}

a Palue was calculated using independent sample t-test.

\begin{tabular}{|c|c|c|c|c|c|c|c|c|c|c|c|c|}
\hline \multirow{3}{*}{$\begin{array}{l}\text { Leq, } 8 \mathrm{~h}, \\
\text { dB }\end{array}$} & \multicolumn{6}{|c|}{ Rest Day } & \multicolumn{6}{|c|}{ Work Day } \\
\hline & \multicolumn{3}{|c|}{ Worker } & \multicolumn{3}{|c|}{ Control } & \multicolumn{3}{|c|}{ Worker } & \multicolumn{3}{|c|}{ Control } \\
\hline & Number & 95\% CI & PValue $^{\mathrm{a}}$ & Number & 95\% CI & P Value $^{\mathrm{a}}$ & Number & 95\% CI & PValue $^{\mathrm{a}}$ & Number & 95\% CI & P Value $^{\mathrm{a}}$ \\
\hline$<70$ & 61 & $0.12(-0.27-0.6)$ & 0.6 & 60 & $-0.44(-0.2-0.2)$ & 0.7 & - & - & - & 50 & $0.15(-0.19-0.5)$ & 0.5 \\
\hline$\geq 70-\leq 80$ & 39 & $0.69(-1.2-2.5)$ & 0.4 & 40 & $0.75(-1.4-2.3)$ & 0.3 & 45 & $-0.65(-1.66-0.35)$ & 0.1 & 50 & $0.7(-1.8-3)$ & 0.1 \\
\hline$>80$ & - & - & - & - & - & - & 55 & $3.67(1.43-5.91)$ & 0.002 & - & - & - \\
\hline
\end{tabular}

${ }^{\text {a }}$ palue $<0.05$.

\section{Discussion}

In this study, in case and control groups, morning saliva cortisol concentrations for both rest and work days were similar with no significant difference. For the two groups in rest day samples, the morning salivary cortisol concentrations were roughly 2.5 to 3 times higher than the evening levels, as shown by previous studies (24-26). In control group, the evening cortisol levels in work day and rest day schedules were similar. Nevertheless, in workers' group (exposure with noise higher than $80 \mathrm{dBA}$ in 45 participants), this was significant in the amount of cortisol secretion $(\mathrm{P}<0.05)$. Very similar to our findings, Hebert et al. assessed the effects of noise exposure on cortisol levels and subjective stress in patients with tinnitus and controls without tinnitus. Their results showed higher cortisol levels for both groups immediately before, immediately after, and 10 minutes after the end of noise exposure than other time points. Their Overall results showed that noise exposure influences cortisol response and subjective stress (27). Melamed et al. assessed the effects of chronic industrial noise exposure on urinary cortisol, fatigue and irritability in 32 healthy industrial workers. These workers were chronically exposed to high ambient noise levels (> $85 \mathrm{dBA}$ ) without using ear protectors. The results of this study showed that the urinary cortisol level at the end of the workday was significantly higher $(\mathrm{P}<0.05)$ under chronic noise condition compared to attenuated noise condition (3). This findings support the results of the present study. Waye et al. assessed salivary free cortisol concentrations, rated stress and annoyance in 32 subjects before, during and after doing some tasks for 2 hours during exposure to ventilation noise, with dominant low frequencies. The study showed physiological evidence (saliva cortisol) of increased stress related to noise sensitivity and noise exposure during work (6). Waye et al. in another study assessed the effects of nighttime exposure to traffic noise or low frequency noise on the cortisol awakening response and subjective sleep quality. This study showed that night time exposure to low frequency noise may affect the cortisol response upon wake up and also lower cortisol levels after awakening were associated with subjective reports of lower sleep quality and mood (28). Gitanjali et al. performed a study to find out whether acute exposure of healthy individuals to loud occupational noise during the daytime would cause changes in their nocturnal sleep, architecture, heart rate during sleep and serum cortisol levels. Their results showed that serum cortisol levels increased significantly after exposure to noise (29).

Miki et al. assessed urinary and salivary stress hormone levels while performing arithmetic calculations in a noisy environment. Their results showed higher cortisol levels during performing the task in noisy environment compared to pretask levels of cortisol, and cortisol in quiet conditions (30). These results all support the findings presented in this paper, as noise exposure in industrial settings increases saliva cortisol concentrations significantly. Although there are some other studies which found no significant association between noise exposure and salivary cortisol increase (5, 31-33); noise levels mentioned in these studies were not of industrial kind, it was 
in general road traffic noise or air craft noise with levels under $60 \mathrm{dBA}$. In this study, the noise exposure schedule and its nature for control group was similar to these studies and similarly no significant effect was obsereved due to noise exposure on salivary cortisol elevation. In conclusion, exposure to noise levels below 75 dBA cannot be contributed to secretion of salivary cortisol above the normal levels. In workers' group, exposure to high levels of industrial noise (> $80 \mathrm{dBA}$ ) strongly and significantly increased evening saliva cortisol levels. This study showed that exposure to industrial noise levels above 80 dBA can increase salivary cortisol level above the normal levels. In addition, our study revealed that industrial noise and ambient noise with levels below $80 \mathrm{dBA}$ has no significant effect on salivary cortisol elevation. More extensive studies should be performed on industrial noise exposure effects on stress-induced responses in affected subjects. Salivary cortisol investigation as a simple and noninvasive method has demonstrated its feasibility in this study and is suggested to be used in future studies in this field.

\section{Acknowledgements}

The authors appreciate the participants for their interest and enthusiasm to participate in the study.

\section{Funding/Support}

The study was funded by School of Public Health, Tehran University of Medical Sciences.

\section{References}

1. Kjellberg A. Subjective, behavioral and psychophysiological effects of noise. Scand J Work Environ Health. 1990;16 Suppl 1:29-38.

2. Melamed S, Luz J, Green MS. Noise exposure, noise annoyance and their relation to psychological distress, accident and sickness absence among blue-collar workers--the Cordis Study. Isr J Med Sci.1992;28(8-9):629-35.

3. Melamed S, Bruhis S. The effects of chronic industrial noise exposure on urinary cortisol, fatigue and irritability: a controlled field experiment. J Occup Environ Med.1996;38(3):252-6.

4. World Health Organization.. Guidelines for Community Noise Geneva: WHO; 2000. Available from: http://whqlibdoc.who.int/ hq/1999/a68672.pdf.

5. Selander J, Bluhm G, Theorell T, Pershagen G, Babisch W, Seiffert I, et al. Saliva cortisol and exposure to aircraft noise in six European countries. Environ Health Perspect. 2009;117(11):1713-7.

6. Waye KP, Bengtsson J, Rylander R, Hucklebridge F, Evans P, Clow A. Low frequency noise enhances cortisol among noise sensitive subjects during work performance. Life Sci. 2002;70(7):745-58.

7. Ockenfels MC, Porter L, Smyth J, Kirschbaum C, Hellhammer DH, Stone AA. Effect of chronic stress associated with unemployment on salivary cortisol: overall cortisol levels, diurnal rhythm, and acute stress reactivity. Psychosom Med.1995;57(5):460-7.

8. Bigert C, Bluhm G, Theorell T. Saliva cortisol--a new approach in noise research to study stress effects. Int J Hyg Environ Health. 2005;208(3):227-30.

9. Laudat MH, Cerdas S, Fournier C, Guiban D, Guilhaume B, Luton JP. Salivary cortisol measurement: a practical approach to assess pituitary-adrenal function. J Clin Endocrinol Metab. 1988; 66(2):343-8.

10. Vining RF, McGinley RA. The measurement of hormones in saliva: possibilities and pitfalls. J Steroid Biochem. 1987;27(1-3):81-94.
11. Walker RF. Salivary cortisol determinations in the assessment of adrenal activity. Front Oral Physiol. 1984;27:81-94.

12. Vining RF, McGinley RA, Maksvytis JJ, Ho KY. Salivary cortisol: a better measure of adrenal cortical function than serum cortisol. Ann Clin Biochem. 1983;20 (Pt 6):329-35.

13. Riad-Fahmy D, Read GF, Walker RF, Griffiths K. Steroids in saliva for assessing endocrine function. Endocr Rev. 1982;3 (4):367-95.

14. Carrasco GA, Van de Kar LD. Neuroendocrine pharmacology of stress. Eur J Pharmacol. 2003;463(1-3):235-72.

15. Dickmeis T. Glucocorticoids and the circadian clock.J Endocrinol. 2009;200(1):3-22.

16. Dorn LD, Lucke JF, Loucks TL, Berga SL. Salivary cortisol reflects serum cortisol: analysis of circadian profiles. Ann Clin Biochem. 2007;44(Pt 3):281-4.

17. Hucklebridge F, Hussain T, Evans P, Clow A. The diurnal patterns of the adrenal steroids cortisol and dehydroepiandrosterone (DHEA) in relation to awakening. Psychoneuroendocrinology. 2005;30(1):51-7.

18. Knutsson U, Dahlgren J, Marcus C, Rosberg S, Bronnegard M, Stierna P, et al. Circadian cortisol rhythms in healthy boys and girls: relationship with age, growth, body composition, and pubertal development. J Clin Endocrinol Metab. 1997;82(2):536-40.

19. Miller GE, Chen E, Zhou ES. If it goes up, must it come down? Chronic stress and the hypothalamic-pituitary-adrenocortical axis in humans. Psychol Bull. 2007;133(1):25-45.

20. Kirschbaum C, Hellhammer DH. Salivary cortisol in psychoneuroendocrine research: recent developments and applications. Psychoneuroendocrinology. 1994;19(4):313-33.

21. Meeran K, Hattersley A, Mould G, Bloom SR. Venepuncture causes rapid rise in plasma ACTH. Br J Clin Pract.1993;47(5):246-7.

22. Smyth J, Ockenfels MC, Porter L, Kirschbaum C, Hellhammer DH, Stone AA. Stressors and mood measured on a momentary basis are associated with salivary cortisol secretion. Psychoneuroendocrinology.1998;23(4):353-70.

23. Lewis HB, Douglas HB. Sound measurement and analysis. Industrial noise control. 2th ed. New York: Marcel Dekker;1994. pp.135-86.

24. Van CE, Turek FW. Endocrine and other biological rhythms. In: DeGroot LJ editor. Endocrinology.. Philadelphia: Saunders; 1994. pp. 2487-48.

25. Wust S, Wolf J, Hellhammer DH, Federenko I, Schommer N, Kirschbaum C. The cortisol awakening response - normal values and confounds. Noise Health. 2000;2(7):79-88.

26. Yang Y, Koh D, Ng V, Lee FC, Chan G, Dong F, et al. Salivary cortisol levels and work-related stress among emergency department nurses. J Occup Environ Med. 2001;43(12):1011-8.

27. Hebert S, Lupien SJ. Salivary cortisol levels, subjective stress, and tinnitus intensity in tinnitus sufferers during noise exposure in the laboratory. Int J Hyg Environ Health. 2009;212(1):37-44.

28. Waye KP, Clow A, Edwards S, Hucklebridge F, Rylander R. Effects of nighttime low frequency noise on the cortisol response to awakening and subjective sleep quality. Life Sci. 2003;72(8):863-75.

29. Gitanjali B, Ananth R. Effect of acute exposure to loud occupational noise during daytime on the nocturnal sleep architecture, heart rate, and cortisol secretion in healthy volunteers. J Occup Health. 2003;45(3):146-52.

30. Miki K, Kawamorita K, Araga Y, Musha T, Sudo A. Urinary and salivary stress hormone levels while performing arithmetic calculation in a noisy environment. Ind Health.1998;36(1):66-9.

31. Poll RV, Straetemans M, Nicolson NA. Ambient noise in daily life: a pilot study. In: Boone R editor. Internoise 2001. Proceedings of the 2001 International Congress and Exhibition on Noise Control Engineering, The Hague.. Maastricht: Nederlands Akoestisch Genootschap; 2001. p. 1807-10.

32. Stansfeld SA, Brentnall SL, Haines MM. Investigating the effects of noise exposure on stress hormone response in children. In: Boone R editor. Internoise 2001 Proceedings of the 2001 International Congress and Exhibition on Noise Control Engineering, The Hague.. Maastricht: Nederlands Akoestisch Genootschap; 2001. p.1723-28.

33. Michaud DS, Miller SM, Ferrarotto C, Konkle AT, Keith SE, Campbell $\mathrm{KB}$. Waking levels of salivary biomarkers are altered following sleep in a lab with no further increase associated with simulated night-time noise exposure. Noise Health. 2006;8(30):30-9. 